\title{
ANÁLISE DA PRODUÇÃO DE LEITE E DE CANA-DE-AÇÚCAR NO MUNICÍPIO DE RUBIATABA, GOIÁS
}

\author{
Mirian Fabiana da Silva ${ }^{1}$, Angélica Cáritas da Silva ${ }^{2}$
}

\begin{abstract}
RESUMO - Este estudo objetivou analisar a evolução da produção de leite e de cana-de-açúcar no município de Rubiataba, Goiás, no período de 1985 a 2015, buscando explicar o efeito da expansão da cana-de-açúcar sobre a produção de leite. O município está localizado na microrregião de Ceres, mesorregião do Centro Goiano do estado de Goiás, Brasil. Os dados foram obtidos do Instituto Brasileiro de Geografia e Estatística nos anos de 1985 a 2015. Analisou-se o efetivo de rebanho, produção de leite, produtividade por vaca, número de vacas, área colhida, produção e produtividade de cana-de-açúcar e valores das produções. Utilizou-se de análises de regressões lineares simples para avaliar as taxas anuais de crescimento da produção leiteira e cana-de-açúcar. Para comparar as duas produções agropecuárias foram realizadas correlações de Pearson. Ao longo do período analisado, a produção de leite cresceu $2,10 \%$ ao ano. A produtividade por vaca cresceu 1,60\% ao ano no período. A produção em 2015 foi de 23,00 milhões litros e a produtividade animal de 1.353 litros/vaca/ ano. A área colhida e a produção de cana-de-açúcar cresceram 2,99\% e 2,59\% ao ano, respectivamente, de 1985 a 2015. A produtividade da cana-de-açúcar não aumentou. A produção de cana-de-açúcar foi de 355.881 toneladas e a produtividade de 63 toneladas/ha, em 2015. Os valores das produções de leite e cana-de-açúcar em 2015 foram R \$ 20,16 milhões e R\$ 19,68 milhões, respectivamente. A correlação entre as duas produções foi de 0,548 , ou seja, ambas as atividades evoluíram. O cultivo de cana-de-açúcar aumentou a produção pela expansão da área colhida, portanto precisa melhora a produtividade por área. A pecuária leiteira conseguiu aumentar a produção por meio da melhoria da produtividade por vaca. Ao comparar a evolução da produção das duas atividades, pode afirmar que a produção de leite evoluiu mesmo com a expansão da cana-de-açúcar no município.
\end{abstract}

Palavras chave: agronegócio, desenvolvimento, eficiência produtiva, produtividade.

\section{ANALYSIS OF MILK AND SUGARCANE PRODUCTION IN THE MUNICIPALITY OF RUBIATABA, GOIÁS}

\begin{abstract}
This study aimed to analyze the evolution of milk and sugarcane production in the municipality of Rubiataba, Goiás, in the period from 1985 to 2015, seeking to explain the effect of the expansion of sugarcane on milk production. The municipality is located in the Ceres microregion, a mesoregion of the Goiano Center in the state of Goiás, Brazil. The data were obtained from the Brazilian Institute of Geography and Statistics from 1985 to 2015. The herd size, milk production, cow productivity, number of cows, area harvested, production and productivity and the production values were analyzed. Simple linear regression analyses were used to evaluate the annual growth rates of both milk and sugarcane production. In order to compare the two agricultural production systems, Pearson correlations were calculated between the two activities. During the analyzed period, milk production grew by $2.10 \%$ per year. Productivity per cow increased to $1.60 \%$ per year in the period. Production in 2015 was 23.00 million liters and animal productivity of 1,353 liters/cow/year. The area harvested and the production of sugarcane increased by $2.99 \%$ and $2.59 \%$ per year, respectively, from 1985 to 2015. Sugarcane productivity did not increase. The production of sugarcane was 355,881 tons and the productivity of 63 tons/ha in 2015. The values of the production of milk and sugarcane in 2015 were $R \$ 20.16$ million and $R \$ 19.68$ million, respectively. The correlation between the two productions was 0.548 ,
\end{abstract}

\footnotetext{
${ }^{1}$ Doutoranda do Programa de Pós-graduação em Nutrição e Produção Animal, Universidade de São Paulo, Faculdade de Medicina Veterinária e Zootecnia, Pirassununga, São Paulo (e-mail: mirian.zootecnista@gmail.com).

${ }^{2}$ Especialista em Gestão em Agronegócio, Universidade Estadual de Goiás.
} 
that is, both activities evolved. Sugarcane cultivation increased production by expanding the area harvested, but it needs to improve productivity per area. Dairy farming has been able to increase production by improving productivity per cow. When comparing the evolution of the production of the two activities, it can be affirmed that the milk production evolved even with the expansion of sugarcane.

Keywords: agribusiness, development, production efficiency, productivity.

\section{INTRODUÇÃO}

No agronegócio brasileiro, a pecuária de leite e o cultivo de cana-de-açúcar têm importância econômica e social. As duas culturas são produzidas praticamente em todo o território nacional. O estado de Goiás ocupa a quarta posição no ranking de maior produção de leite do Brasil, em 2015 possuía 2,5 milhões vacas que produziram 3,5 bilhões de litros de leite, com produtividade de 1.383 litros/vaca/ano (IBGE, 2017a). A atividade leiteira é desenvolvida em todos os municípios goianos.

A produção de leite, nas últimas décadas, principalmente no início dos anos noventa, vem passando por diversas transformações; destacando-se o deslocamento de bacias leiteiras para regiões não tradicionais como produtoras de leite, o aumento da produção e do consumo de lácteos, e ainda o aumento das exigências em relação à qualidade do leite. O aumento da produção foi proporcionado pelas inovações tecnológicas e também pelos ajustes nos sistemas de produção a pasto e incremento da produção em escala.

O cultivo de cana-de-açúcar no Brasil vem expandindo desde a implantação do Programa Nacional do Álcool (Proálcool) em 1975, passando por um período de estagnação na década de 1990. Na década 2000 a expansão deve-se ao retorno dos incentivos à produção do etanol, principalmente com o desenvolvimento dos veículos bicombustíveis, que utilizam álcool e gasolina. Na safra de 2014/2015, o estado de São Paulo foi o maior produtor de cana-de-açúcar, com 341,59 milhões toneladas, e o estado de Goiás foi o segundo produtor, com 66,33 milhões toneladas (Conab, 2015).

A atividade sucroalcooleira se expandiu rapidamente, com isto tem gerado vários questionamentos sobre o impacto na produção de outras atividades agropecuárias. Segundo vários autores (Castro et al., 2010; Ávila et al., 2011; Sauer \& Pietrafesa, 2012; Araújo, 2013; Aguiar \& Souza, 2014) o aumento da área cultivada com cana-de-açúcar provocou redução nas áreas de cultivos alimentares, principalmente na produção de arroz, feijão, milho, café, algodão, laranja e pecuária.
No entanto, de acordo com Kohlhepp (2010), o aumento do plantio da cana-de-açúcar não causou escassez de gêneros alimentícios, a redução da área de produção de alimentos foi compensada pelo aumento da produtividade.

Diante desse contexto, levanta-se a questão: A produção de leite no município de Rubiataba, Goiás, reduziu com a expansão do cultivo de cana-de-açúcar? O município foi escolhido por ser um importante produtor de cana-de-açúcar da microrregião de Ceres, Goiás. A economia de Rubiataba está associada à atividade agropecuária, formada por pequenos e médios produtores. Outro aspecto é pelo fato da usina sucroalcooleira, instalada no município no início da década de 1980, ter sido criada na forma de cooperativa. Além da cooperativa ligada ao setor sucroalcooleiro, Rubiataba possui uma cooperativa agropecuária que capta o leite dos produtores da região e desenvolve outras ações ligadas à pecuária. Estas cooperativas possibilitaram o crescimento e desenvolvimento econômico e social do município.

Objetivou-se analisar a evolução da produção e produtividade da atividade de leite e de cana-de-açúcar no município de Rubiataba, Goiás, no período de 1985 a 2015, buscando explicar o efeito da expansão da canade-açúcar sobre a produção de leite.

\section{MATERIALE MÉTODOS}

A pesquisa foi fundamentada em uma abordagem de análise quantitativa (Rampazzo, 2011). O estudo é de natureza descritiva, o qual avaliou a produção e produtividade da atividade de bovinocultura leiteira e de cana-de-açúcar no município de Rubiataba, Goiás.

O município está localizado na microrregião de Ceres, na mesorregião do Centro Goiano do estado de Goiás, Brasil, a 213 km de Goiânia. Os municípios limítrofes são: a leste, Ceres e Ipiranga de Goiás; a norte, Itapaci e Nova América; a oeste, Morro Agudo de Goiás e Araguapaz; a sul, São Patrício (Figura 1). Rubiataba foi elevada de povoado diretamente a cidade 
em 1953, possui área territorial de 748,26 km², com uma população estimada em 2015 de 19.832 habitantes (IBGE, 2017b).

Os dados foram obtidos do Instituto Brasileiro de Geografia e Estatística (IBGE) nos anos de 1985 a 2015, com ênfase na produção de leite, no efetivo de rebanho, no número de vacas, na área colhida e na produção de cana-de-açúcar e nos valores das produções no município. Os valores das produções foram deflacionados pelo Índice Geral de Preços Disponibilidade Interna (IGP-DI) da Fundação Getúlio Vargas, para agosto de 2017.

Desta forma, analisou-se a característica produtiva do município, por meio de cálculos das taxas médias de crescimento anual e da análise de Correlação de Pearson para observar se as duas atividades apresentam correlações.

As taxas médias de crescimento anual foram calculas com base em uma regressão linear simples. Onde, dado $\mathrm{t}$ valores de uma variável $\mathrm{X}_{\mathrm{t}}$ em estudo com um valor inicial de $\mathrm{X}_{1}$ conforme a fórmula:

$$
X_{t}=X_{1}(1+r)^{t}
$$

Aplicando-se logaritmos sobre a mesma, obtém-se:

$$
\log X_{t}=\log X_{1}+t \log (1+r)
$$

Que corresponde a equação linear:

$$
\mathrm{Y}_{\mathrm{i}}=\mathrm{a}+\hat{\mathrm{a} t}
$$

Onde: $\mathrm{Yi}=\log \mathrm{Xt}, \mathrm{a}=\log \mathrm{X} 1, \hat{\mathrm{a}}=\log (1+\mathrm{r})$ e $\mathrm{r}=$ (antilog â) -1

A análise de correlação de Pearson procura determinar o grau de relacionamento entre duas variáveis. Essa análise foi utilizada para medir a relação linear entre a produção de leite, efetivo de rebanho, número de vacas, produtividade por vaca por ano, área colhida, produção e produtividade de cana-de-açúcar e os valores das produções. O coeficiente de correlação (r) de uma variável X em relação à variável Y é calculado usado a seguinte fórmula:

$$
r=\frac{n \Sigma X i Y i-(\Sigma X i)(\Sigma Y i)}{\sqrt{\left[n \Sigma X^{2}-(\Sigma X i)^{2}\right]\left[n \Sigma i^{2}-(\Sigma Y i)^{2}\right]}}
$$

As análises foram processadas utilizado o software estatístico Minitab® 17.1.0 (Minitab, 2010), adotou-

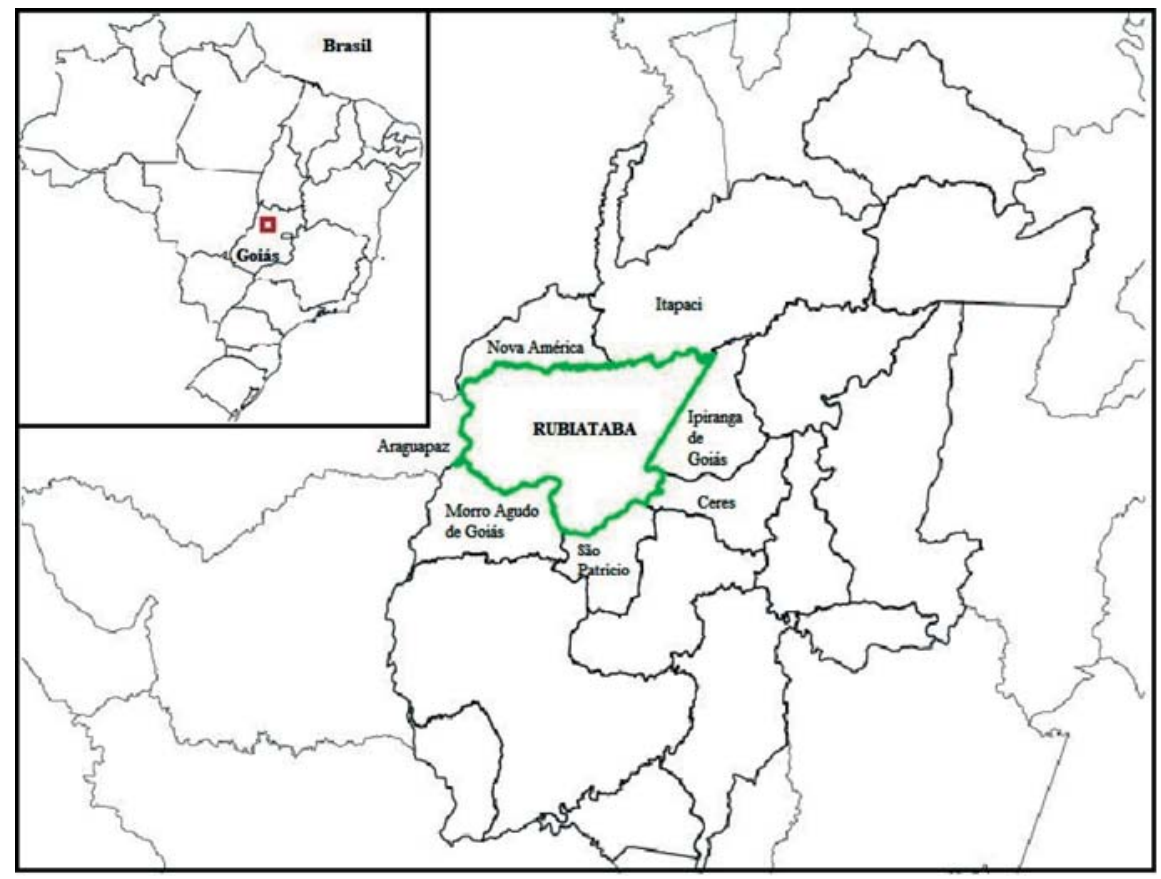

Figura 1 - Mapa do município de Rubiataba, Goiás.

Fonte: IBGE (2017b), elaborado pelas autoras. 
se um nível de confiança de 95\%. As tabelas e figuras foram feitas com o uso do software Excel ${ }^{\circledR}$.

\section{RESULTADOS E DISCUSSÃO}

O município de Rubiataba, em 2006, segundo o IBGE, possuía uma área total de terras utilizada de 68.330 ha. A área total de pastagens era de 43.804 ha, sendo 29.173 ha naturais e 14.631 ha plantadas. A área de cultivo possuía 180 ha para lavouras permanentes e 18.013 ha para lavouras temporárias. A área de matas naturais era de 5.678 ha e matas plantadas de 129 ha (IBGE, 2017c).

Segundo os dados do Censo Agropecuário de 1985, 1995-1996 e 2006 (IBGE, 1991; 1997; 2017c) a área de lavouras permanentes e temporárias em 1985 correspondia $12,52 \%$ da área do município, houve redução em 1995 para 7,93\% e em 2006 aumentou para $26,63 \%$. A área de pastagens naturais e plantadas em 1985 e 1995 representava 82,17\% e 82,85\%, respectivamente, apresentou redução em 2006 para $64,11 \%$. A área com matas naturais e plantadas evoluiu de 2,10\% em 1985 para 5,82\% em 1995 e 8,50\% em 2006.

A economia do município de Rubiataba sempre foi associada às atividades agrícolas e pecuárias, formada por pequenos e médios produtores. Por isso, em 1971 os produtores rurais criaram uma cooperativa (Cooperativa Regional Agropecuária de Rubiataba Cooper-Agro), para melhor desenvolver as atividades e obter recursos econômicos. Essa cooperativa existe atualmente e ao longo dos anos vem contribuindo para o fortalecimento da bacia leiteira da região, como a captação do leite a granel, além de possuir uma loja agropecuária.

A produção de leite no período de 1985 a 2015 apresentou um crescimento médio de 2,10\% ao ano ( $\mathrm{P}<0,001$ e R² 72,20\%). A produção de leite manteve-se praticamente estável entre os anos de 1985 a 1995, apresentando a partir de então um crescimento considerável até o ano de 2005, com uma produção de 24,62 milhões de litros. Nos anos de 2006 e 2007 houve um declínio e depois um leve aumento nos anos seguintes, obtendo em 2015, 23,00 milhões de litros (Figura 2).

O preço do litro de leite passou por oscilações no período analisado, o aumento do valor total da produção se deve ao crescimento da produção. O preço do litro de leite na década de 80 foi em média $R \$ 1,30$, nos anos seguintes houve queda chegando a R\$ 0,44 em 1993. A partir de 1994, com a mudança da moeda o preço apresentou oscilações, com média de R \$ 0,83 (Figura 2).

O efetivo do rebanho bovino incluindo animais de corte e leite vem apresentado um leve crescimento anual médio de 0,44\% ( $\mathrm{P}<0,001$ e R² 39,30\%). Em 1985, o município possuía 74.600 cabeças, evoluindo para 98.000 em 2015. Ao observar a Figura 3, verifica-se que o rebanho oscilou ao longo dos anos, em 1989 e 1996 apresentaram o menor número de animais (56.000

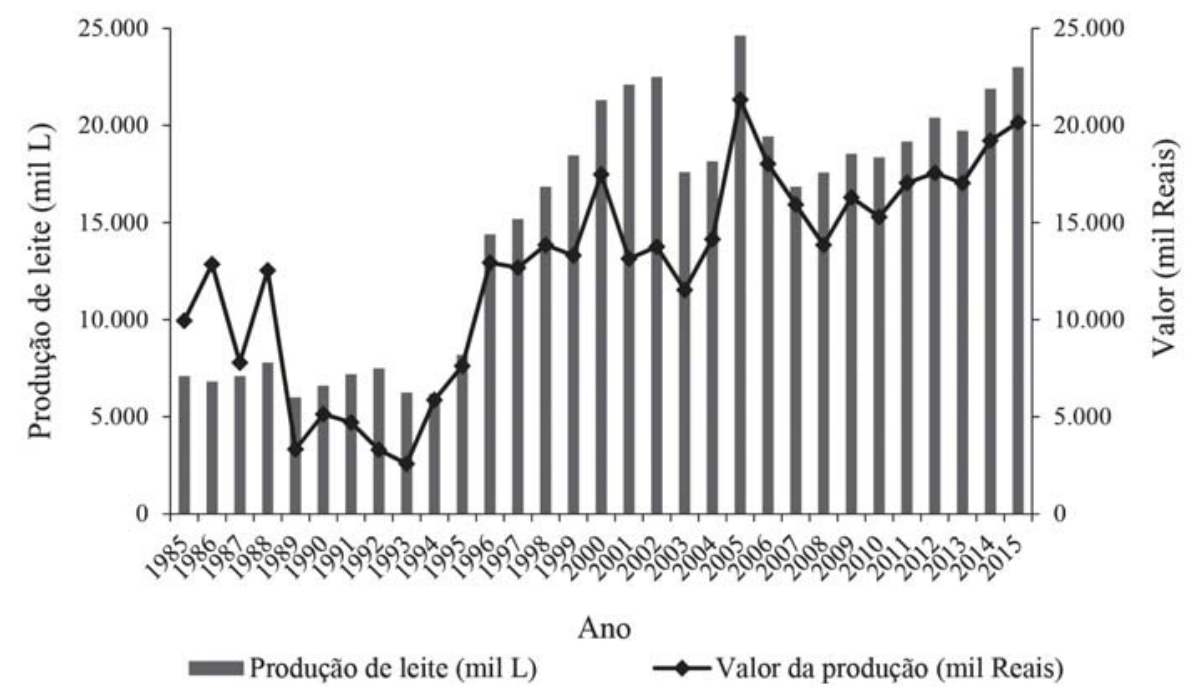

Figura 2 - Produção de leite e o valor da produção nos anos de 1985 a 2015, no município de Rubiataba, Goiás. Fonte: IBGE (2017a), elaborado pelas autoras. 
cabeças). A quantidade de vacas era de 12.500 cabeças em 1985, passando para 17.000 em 2015. O número de vacas acompanha as oscilações ocorridas no rebanho, ou seja, se o rebanho aumenta a quantidade de vacas também aumenta. Tal fato esse que é explicado pela correlação $(0,704)$ significativa $(\mathrm{P}<0,05)$ entre essas duas variáveis (Tabela 2). O ano de 1989 apresentou o menor número de vacas (10.000 cabeças). Observase que houve um aumento em 2005 (19.000 cabeças), depois ocorreu redução e a partir de 2009 houve um leve aumento no número de vacas (Figura 3).
A produtividade de leite por animal vem aumentando em média de 1,61\% ao ano ( $\mathrm{P}<0,001$ e $\mathrm{R}^{2} 65 \%$ ) no período de 1985 a 2015. Entre 1985 e 1995 a produtividade não aumentou, mantendo-se estável em média de 579 litros/ vaca/ano. Em 1996 este indicador foi para 1.200 litros/ vaca/ano, alcançando em 2002 o maior volume, que foi de 1.480 litros/vaca/ano; já nos dois anos seguintes houve redução para 1.100 litros/vaca/ano. Em 2005 houve um aumento na produtividade animal e após esse período manteve-se praticamente estável, em 2015 foi de 1.353 litros/vaca/ano (Figura 4).

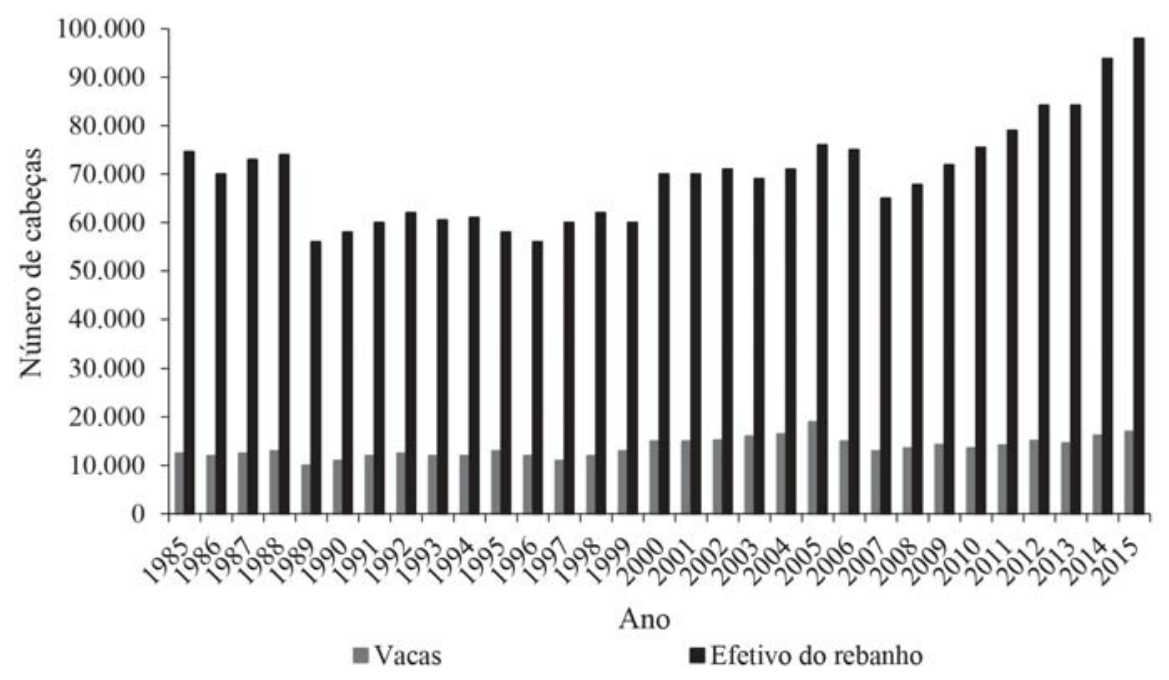

Figura 3 --Efetivo do rebanho bovino corte e leite e número de vacas em cabeças, no município de Rubiataba, Goiás, de 1985 a 2015.

Fonte: IBGE (2017a), elaborado pelas autoras.

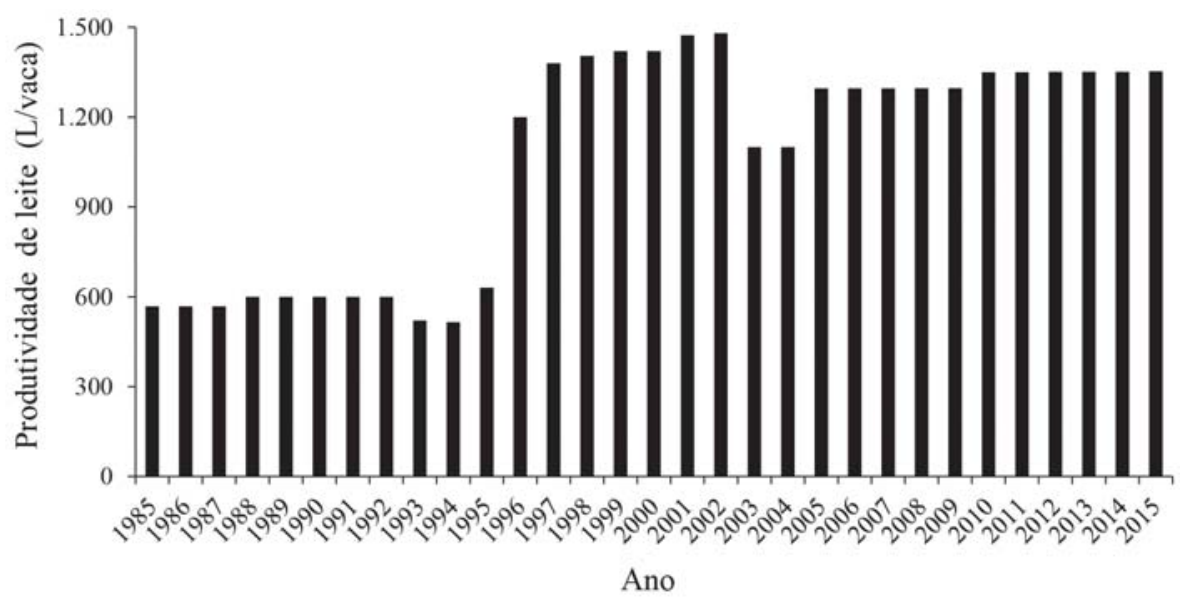

Figura 4 - Produtividade por vaca no município de Rubiataba, Goiás, de 1985 a 2015.

Fonte: IBGE (2017a), elaborado pelas autoras. 
A produtividade por vaca em 2015, no município, foi superior à produtividade média das fazendas da região do Extremo Sul da Bahia em 2002 de 1.234 litros/ vacas/ano (Oliveira et al., 2007). Esse indicador no estado de Goiás em 2015 foi de 1.383 litros/vaca/ano. No Brasil foi superior ao analisado, de 1.609 litros/ vaca/ano em 2015 (IBGE, 2017a). Pereira et al. (2016) analisaram fazendas produtoras de leite da mesorregião Triângulo Mineiro-Alto Paranaíba, Minas Gerais, encontraram média de 3.383 litros/vaca/ano, sendo a menor de 1.067 e a maior de 8.124 litros/vaca/ano. Esse indicador é influenciado pelo sistema de produção adotado, pela genética dos animais, pela nutrição e pelo manejo reprodutivo e sanitário do rebanho.

Na década de 80, o Brasil enfrentou uma crise econômica, que levou à diminuição na demanda por leite e derivados, desestimulando a produção leiteira nacional. Os produtores desestimulados e sem capacidade de investimento, não aplicaram tecnologias para aumentar a produção e produtividade, e como consequência a produtividade ficou praticamente estagnada (Martins, 1992). Fato que pode ser observado no município de Rubiataba entre os anos de 1985 e 1994 (Figura 4).

As transformações na produção de leite nos anos 90 foram decorrentes principalmente do fim do tabelamento do preço do leite, da estabilização da economia brasileira com a criação do Plano Real e da criação do Mercado Comum do Sul (Mercosul). Após 1995, a produtividade por vaca assumiu maior importância como fonte de crescimento da produção de leite do município (Figura 4).

No ano de 2005, quando a produção de leite foi a maior do período analisado, esse volume deveu-se ao aumento do número de vacas, que também foi o maior no período. O que caracteriza um crescimento extensivo da produção de leite.

Nos últimos anos, o aumento da renda per capita, a exigência por melhor qualidade e o aumento da concorrência em todos os elos da cadeia produtiva do leite tem exigido dos produtores ajustes nos sistemas de produção, incremento da produção em escala e inovações tecnológicas.

A pecuária leiteira neste município tem muitos aspectos para melhorar, como a sanidade do rebanho, a qualidade do leite produzido, a produtividade por animal e por área, a alimentação - principalmente no período de seca -, a administração, dentre outros. Dessa maneira, investimentos em pesquisa, esforços em transferência de tecnologia e disponibilidade de linha de créditos devem ser direcionados para os pontos de estrangulamentos detectados nesta região, a fim de obter uma produção rentável e sustentável.

O município tem evoluído na atividade sucroalcooleira, principalmente pela implantação da Cooperativa Agroindustrial de Rubiataba (Cooper-Rubi) no início da década de 1980. Inicialmente começou com a produção de álcool e posteriormente passou a produzir açúcar. A criação da cooperativa foi por incentivos públicos para a produção de etanol, diante da necessidade de diversificar a matriz energética do país, principalmente com a atuação do Programa Nacional do Álcool (Proálcool).

A área colhida de cana-de-açúcar cresceu em média 2,99\% ao ano ( $\mathrm{P}<0,001$ e R $\mathrm{R}^{2}$ 72,40\%), desde 1985 a 2015. Em 1985 foi de 289 ha, em 1986 possuía uma área de 1.963 ha, a partir de então houve oscilação na área colhida de cana-de-açúcar. Em 2003 houve um aumento na área colhida, atingindo em 2008 e 2009 a maior área do período em análise (7.000 ha); a partir desse ano houve leve redução, obtendo em 2015, 5.683 ha (Figura 5).

A produção de cana-de-açúcar cresceu em média 2,59\% ao ano ( $\mathrm{P}<0,001$ e R² 64,50\%), desde 1985 a 2015. Em 1985 foi de 28.900 toneladas, já em 1986 atingiu 196.300 toneladas (Figura 6). Essa rápida expansão na produção foi induzida por política pública como a criação do Proálcool. Na década de 1990 o setor passou pela desregulamentação, ocorrendo certa oscilação na produção. Nesse período o governo eliminou os controles sobre os preços e a produção. Diante dessa situação, as indústrias tiveram que ajustar os aspectos técnicos e produtivos (Ávila et al., 2011). As indústrias também buscaram estratégias competitivas visando redução de custos e aumento de competitividade para se manterem neste novo ambiente competitivo. As empresas diversificaram a produção e buscaram aproveitar os subprodutos, além de adotar novas formas de organização e administração (Moraes, 2007).

Na década de 2000, o setor sucroalcooleiro retoma um novo crescimento com os incentivos à produção de álcool e aos veículos bicombustíveis. No ano de 2003, o grupo Japungu da Paraíba adquiriu 80\% das ações da Cooper-Rubi (Araújo, 2013). Fato que impulsionou o crescimento das atividades 


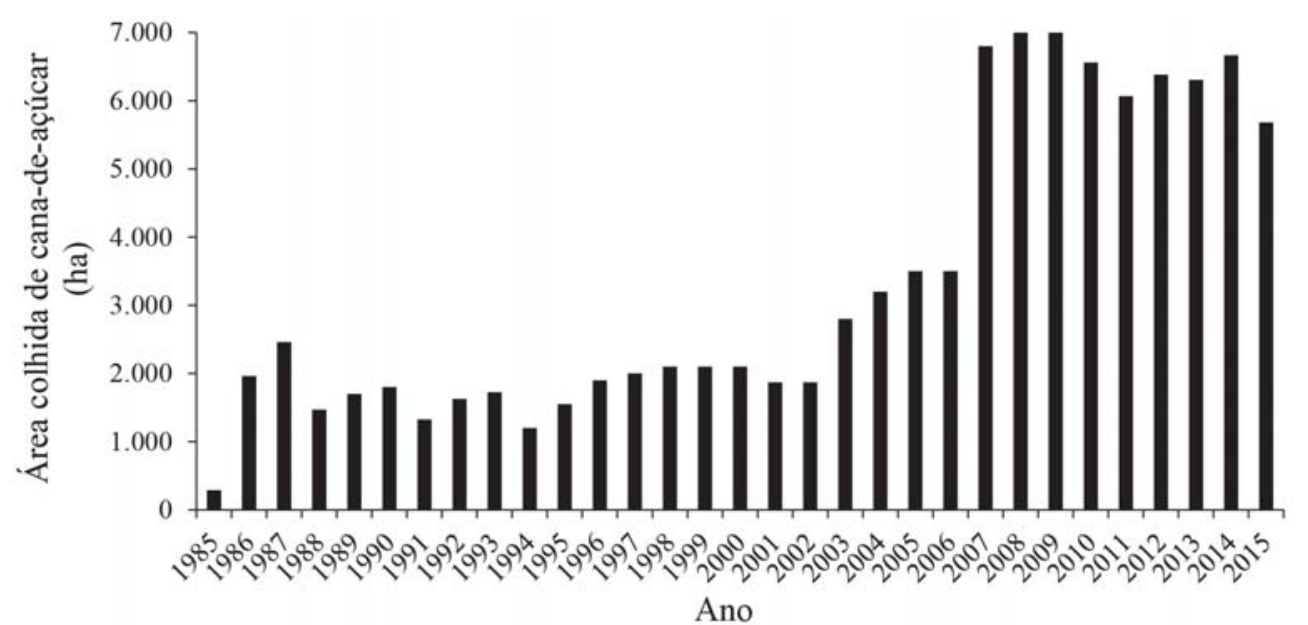

Figura 5 - Área colhida de cana-de-açúcar no município de Rubiataba, Goiás, de 1985 a 2015. Fonte: IBGE (2017a), elaborado pelas autoras.

sucroalcooleiras no município de Rubiataba. Esse crescimento pode ser identificado no aumento da área colhida e na produção de cana-de-açúcar.

O ápice da produção foi nos anos 2008 e 2009, com o maior volume do período em análise de 560.000 toneladas (Figura 6). A partir desse ano houve leve redução, obtendo 355.881 toneladas, em 2015. Essa redução da produção se deve a crise no setor com a redução no valor da tonelada da cana-de-açúcar, com pode ser observado na Figura 6.

A produtividade da cana-de-açúcar praticamente não aumentou, mantendo estável ao longo do período de estudo, com média de 79 toneladas/ha. Ao analisar a Figura 7, observa-se que a produtividade por hectare foi maior nos primeiros anos, de 100 toneladas/ha, e nos últimos anos vêm apresentando redução, em 2015 obteve a menor de 63 toneladas/ha. Esse indicador em 2015 foi inferior ao do estado de Goiás na safra 2014/2015, de 77,65 toneladas/ha (Conab, 2015).

Vários fatores interferem na melhoria da produção e produtividade da cultura da cana-de-açúcar, sendo os principais a interação edafoclimática, o manejo da cultura, a cultivar escolhida, a escolha adequada da área e as técnicas de cultivo (Maule et al., 2001). Ferreira \& Deus (2010), analisaram a produtividade da canade-açúcar na microrregião Ceres e observam que entre os anos de 1984 e 1993 a produtividade cresceu, depois desse período passou por oscilações. As oscilações e reduções na produtividade se devem ao tipo de tecnologia utilizada, uso de áreas menos férteis, degradadas e/ou com topografia com declives acentuados que dificultam a fertirrigação e inserção de maquinários.

Além desses fatores a cultura tem característica semiperene, permite vários cortes sem a necessidade de replantio. Porém, a cada safra precisa-se de manejo adequado de adubações e controle de plantas daninhas, para que a cultura continue sendo produtiva. O replantio ou renovação deve ser realizado devido à redução de produtividade com o aumento do número de corte. No estudo de Sant'Anna et al. (2015) a produtividade média da cana-de-açúcar em fazendas no estado de Goiás foi de $90 \mathrm{t} / \mathrm{ha}$, sendo $114 \mathrm{t} / \mathrm{ha}$ no primeiro corte e 109 t/ha no segundo corte. Nas fazendas do estado de Mato Grosso do Sul a média foi de 85 t/ha, sendo 118 t/ha no primeiro corte e 104 t/ha no segundo corte.

Como pode ser observado na Figura 7, a atividade ao longo do período analisado não melhorou a produtividade por área. O aumento da produção foi possível pelo aumento da área colhida (Figura 5), ou seja, pela incorporação de novas áreas de plantio. A cultura de cana-de-açúcar precisa ser melhor manejada para poder aumentar sua produtividade.

As produções das atividades de leite e de canade-açúcar no município de Rubiataba evoluíram junto, como pode ser observado na Tabela 1. A produção 


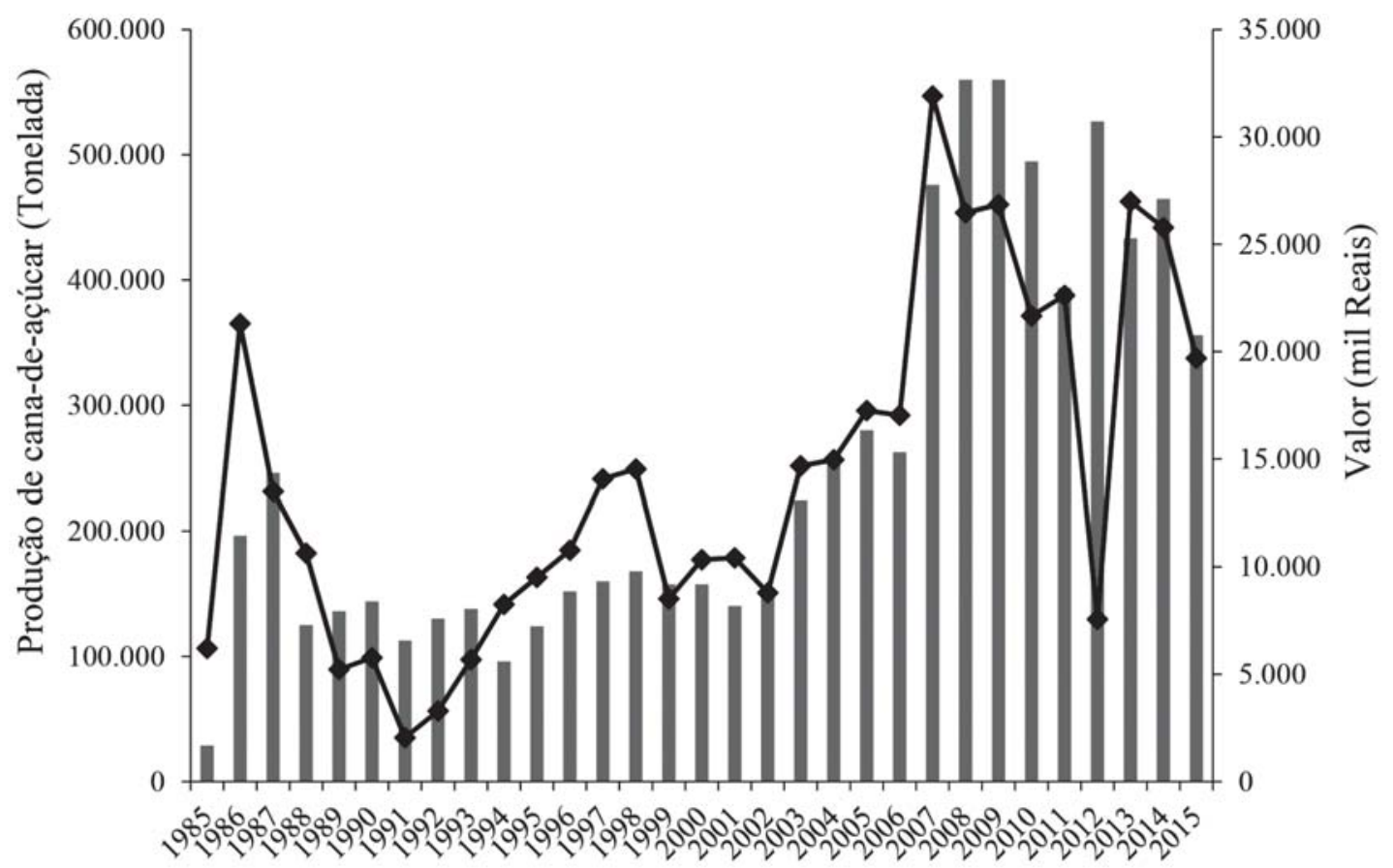

Podução de cana-de-açúcar (Tonelada) $\quad$ —Valor da produção (mil Reais)

Figura 6 - Produção de cana-de-açúcar e o valor da produção no município de Rubiataba, Goiás, de 1985 a 2015. Fonte: IBGE (2017a), elaborado pelas autoras.



Ano

Figura 7 - Produtividade de cana-de-açúcar no município de Rubiataba, Goiás, de 1985 a 2015. Fonte: IBGE (2017a), elaborado pelas autoras. 
de leite e de cana-de-açúcar apresentou crescimento significativo $(\mathrm{P}<0,05)$ em média a $2,10 \%$ ao ano e a $2,59 \%$ ao ano, respectivamente. O efetivo de rebanho, o número de vacas, a produtividade por vaca, a área colhida de cana-de-açúcar e os valores das produções no município apresentaram crescimento significativo $(\mathrm{P}<0,05)$ no período analisado. Somente a produtividade da cana-de-açúcar houve redução, representado por um crescimento negativo (Tabela 1 ).
As variáveis relacionadas à cultura de cana-deaçúcar apresentaram correlação positivas e medianas significativas $(\mathrm{P}<0,05)$ com as variáveis da atividade leiteira, exceto a produtividade da cana-de-açúcar, pelo fato de ter ocorrido redução no período analisado (Tabela 2). Isto significa que ambas as atividades vêm se desenvolvendo no município.

A correlação entre as duas produções foi de 0,548 $(\mathrm{P}=0,001)$, ou seja, as duas atividades cresceram juntas.

Tabela 1 - Taxas médias de crescimento anual das variáveis analisadas no período de 1985 a 2015, no município de Rubiataba, Goiás

\begin{tabular}{lccc}
\hline Variável & Taxa médias de crescimento anual (\%) & P Valor & $\mathrm{R}^{2}$ (\%) \\
\hline Produção de leite (mil L) & 2,10 & $<0,001$ & 72,20 \\
Número de vacas (cabeça) & 0,48 & $<0,001$ & 47,60 \\
Efetivo do rebanho (cabeça) & 0,44 & $<0,001$ & 39,30 \\
Produtividade por vaca por ano (L) & 1,61 & $<0,001$ & 65,00 \\
Valor da produção de leite (mil Reais) & 1,89 & $<0,001$ & 44,50 \\
Área colhida de cana-de-açúcar (ha) & 2,99 & $<0,001$ & 72,40 \\
Produção de cana-de-açúcar (Tonelada) & 2,59 & $<0,001$ & 64,50 \\
Produtividade de cana-de-açúcar (T/ha) & $-0,38$ & $<0,001$ & 57,30 \\
Valor da produção de cana-de-açúcar (mil Reais) & 2,02 & $<0,001$ & 38,60 \\
\hline
\end{tabular}

Fonte: elaborado pelas autoras.

Tabela 2 - Correlação de Pearson e valor-p das variáveis analisadas no período de 1985 a 2015, no município de Rubiataba, Goiás

\begin{tabular}{|c|c|c|c|c|c|c|c|c|}
\hline & $\begin{array}{l}\text { Produção } \\
\text { de leite }\end{array}$ & $\begin{array}{l}\text { Número } \\
\text { de Vacas }\end{array}$ & $\begin{array}{c}\text { Efetivo do } \\
\text { rebanho }\end{array}$ & $\begin{array}{c}\text { Produtividade } \\
\text { por vaca } \\
\text { por ano }\end{array}$ & $\begin{array}{l}\text { Valor da } \\
\text { produção de } \\
\text { leite }\end{array}$ & $\begin{array}{c}\text { Área } \\
\text { colhida de } \\
\text { cana-de-açúcar }\end{array}$ & $\begin{array}{l}\text { Produção de } \\
\text { cana-de- } \\
\text { açúcar }\end{array}$ & $\begin{array}{l}\text { Produtividade } \\
\text { e cana-de- } \\
\text { açúcar }\end{array}$ \\
\hline \multirow[t]{2}{*}{ Número de Vacas } & 0,791 & & & & & & & \\
\hline & $<0,001$ & & & & & & & \\
\hline \multirow[t]{2}{*}{ Efetivo do rebanho } & 0,572 & 0,704 & & & & & & \\
\hline & 0,001 & $<0,001$ & & & & & & \\
\hline \multirow[t]{2}{*}{ Produtividade por vaca por ano } & 0,948 & 0,561 & 0,406 & & & & & \\
\hline & $<0,001$ & 0,001 & 0,023 & & & & & \\
\hline \multirow[t]{2}{*}{ Valor da produção de leite } & 0,875 & 0,741 & 0,708 & 0,813 & & & & \\
\hline & $<0,001$ & $<0,001$ & $<0,001$ & $<0,001$ & & & & \\
\hline \multirow[t]{2}{*}{ Área colhida de cana-de-açúcar } & 0,590 & 0,440 & 0,611 & 0,574 & 0,640 & & & \\
\hline & $<0,001$ & 0,013 & $<0,001$ & 0,001 & $<0,001$ & & & \\
\hline \multirow[t]{2}{*}{ Produção de cana-de-açúcar } & 0,548 & 0,412 & 0,564 & 0,534 & 0,607 & 0,985 & & \\
\hline & 0,001 & 0,021 & 0,001 & 0,002 & $<0,001$ & $<0,001$ & & \\
\hline \multirow[t]{2}{*}{ Produtividade de cana-de-açúcar } & $-0,614$ & $-0,385$ & $-0,300$ & $-0,620$ & $-0,436$ & $-0,533$ & $-0,410$ & \\
\hline & $<0,001$ & 0,033 & 0,101 & $<0,001$ & 0,014 & 0,002 & 0,022 & \\
\hline \multirow{2}{*}{ Valor da produção de cana-de-açúcar } & 0,509 & 0,372 & 0,496 & 0,514 & 0,675 & 0,817 & 0,794 & $-0,370$ \\
\hline & 0,003 & 0,039 & 0,005 & 0,003 & $<0,001$ & $<0,001$ & $<0,001$ & 0,041 \\
\hline
\end{tabular}

Fonte: elaborado pelas autoras. 
Ao comparar a evolução da produção das duas atividades, pode se afirmar que a produção de canade-açúcar não influenciou na produção de leite no município. No período analisado pode ter ocorrido redução da área utilizada pela pecuária, porém houve um aumento na produtividade por animal.

A produção de leite foi influenciada significativamente $(\mathrm{P}<0,05)$ pela produtividade por vaca $(0,948)$, pelo valor da produção de leite $(0,875)$ e pelo número de vacas $(0,791)$. Segundo Resende et al. (2016), o aumento da produtividade por animal pode ser uma meta plausível para melhorar a lucratividade da atividade. O desempenho econômico da atividade está relacionado com vacas mais produtivas e o equilíbrio dos custos de produção, sendo compatível com o potencial produtivo do rebanho do sistema adotado.

O número de vaca foi relacionado significativamente $(\mathrm{P}<0,05)$ com o efetivo do rebanho $(0,704)$, significa que quando houve aumento no rebanho, também ocorreu aumento no número de vacas leiteiras no município ao longo de 1985 a 2015. De acordo com Oliveira et al. (2007), a relação de vacas em lactação pelo total do rebanho apresenta correlação positiva com o desempenho econômico.

O crescimento da produção de cana-de-açúcar no período analisado foi relacionado significativamente $(\mathrm{P}<0,05)$ com a expansão da área colhida $(0,985)$ e com o preço $(0,794)$. Satolo \& Bacchi (2009) e Marques et al. (2012), analisaram a produção de cana-de-açúcar nos estados de São Paulo e Goiás, respectivamente, e concluíram que o preço da cana influenciou o crescimento da produção.

\section{CONCLUSÕES}

A duas atividades desenvolvidas no município de Rubiataba aumentaram suas produções no período de 1985 a 2015. O cultivo de cana-de-açúcar aumentou a produção pela expansão da área colhida, porém precisa melhorar a produtividade por área, a qual apresentou redução no período analisado. A pecuária leiteira conseguiu aumentar a produção por meio da melhoria da produtividade por vaca. Ao comparar a evolução da produção das duas atividades, pode afirmar que a produção de leite evoluiu mesmo com a expansão da cana-de-açúcar no município.

\section{LITERATURA CITADA}

AGUIAR, C.J.; SOUZA, P.M. Impactos do crescimento da produção de cana-de-açúcar na agricultura dos oito maiores estados produtores. Revista Ceres, v.61, n.4, p.482-493, 2014.

ARAÚJO, L.C. Formação territorial do município de Rubiataba (GO): colônia agrícola, rede urbana e atividade sucroalcooleira (1950-2012). Ateliê Geográfico, v.7, n.2, p.196-212, 2013.

ÁVILA, S.R.S.A.; ÁVILA, M.L.; ALTAFIN, I.G. Expansão canavieira no cerrado goiano: crescimento econômico é desenvolvimento?

Organizações Rurais \&

Agroindustriais, v.13, n.3, p.317-329, 2011.

CASTRO, S.S.; ABDALA, K.; SILVA, A.A. et al. A expansão da cana-de-açúcar no cerrado e no estado de Goiás: elementos para uma análise espacial do processo. Boletim Goiano de Geografia, v.30, n.1, p.171-191, 2010.

CONAB-COMPANHIA NACIONAL DE ABASTECIMENTO. Acompanhamento da safra brasileira de cana-de-açúcar. v.2. Brasília: Conab, 2015. 65p.

FERREIRA, L.C.G.; DEUS, J.B. O uso do território e as redes na microrregião Ceres (GO): o caso das agroindústrias sucroalcooleiras. Boletim Goiano de Geografia, v.30, n.2, p.67-80, 2010.

IBGE- INSTITUTO BRASILEIRO DE GEOGRAFIA E ESTATÍSTICA. Censo Agropecuário de 1985 - Goiás. Rio de Janeiro: IBGE, 1991. 588p.

IBGE-INSTITUTO BRASILEIRO DE GEOGRAFIA E ESTATÍSTICA. Censo Agropecuário 19951996 - Goiás. Rio de Janeiro: IBGE, 1997. 257p.

IBGE-INSTITUTO BRASILEIRO DE GEOGRAFIA E ESTATÍSTICA. Censo Agropecuário 2006. In: http://www.ibge.gov.br/estatisticas-novoportal/ economicas/agricultura-e-pecuaria/9827-censoagropecuario.html?edicao=9830 (acessado em 25 de agosto de 2017)c.

IBGE-INSTITUTO BRASILEIRO DE GEOGRAFIA E ESTATÍSTICA.Cidades@. In: http://

cidades.ibge.gov.br/xtras/

perfil.php?lang $=\&$ codmun $=521890$ (acessado em 25 de agosto de 2017)b. 
IBGE-INSTITUTO BRASILEIRO DE GEOGRAFIA E ESTATísticA. Produção Agrícola e Pecuária Municipal - Produção de leite e cana-de-açúcar. In: www.sidra.ibge.gov.br (acessado em 03 de julho de 2017)a.

KOHLHEPP, G. Análise da situação da produção de etanol e biodiesel no Brasil. Estudos Avançados, v.24, n.68, p.223-253, 2010.

MARQUES, D.M.F.; SILVA, T.C.M.; ZOPELARI, A.L.M.S. et al. Produção e preço da cana-deaçúcar em Goiás. Conjuntura Econômica Goiana, n.23, p.31-43, 2012.

MARTINS, R. S. Análise da política de preço do leite no Brasil, 1960-87. Dissertação (Mestrado em Economia Rural). Viçosa, MG: UFV, 1992. 70p.

MAULE, R.F.; MAZZA, J.A.; MARTHA JUNIOR. G.B. Produtividade agrícola de cultivares de canade-açúcar em diferentes solos e épocas de colheita. Scientia Agricola, v.58, n.2, p.295301, 2001.

MINITAB. Minitab ${ }^{\circledR}$ 17.1.0 Statistical

Software. State College, PA: Minitab, 2010.

MORAES, M.A.F.D. Indicadores do mercado de trabalho do sistema agroindustrial da cana-deaçúcar do Brasil no período 1992-2005. Estudos Econômicos, v.37, n.4, p.875-902, 2007.
OLIVEIRA, A.S.; CUNHA, D.N.F.V.; CAMPOS, J.M.S. et al. Identificação e quantificação de indicadores-referência de sistemas de produção de leite. Revista Brasileira de Zootecnia, v.36, n.2, p.507-516, 2007.

PEREIRA, M.N.; RESENDE, J.C.; PEREIRA, R.A.N. et al. Indicadores de desempenho de fazendas leiteiras de Minas Gerais. Arquivo Brasileiro de Medicina Veterinária e Zootecnia, v.68, n.4, p.1033-1042, 2016.

RAMPAZZO, L. Metodologia científica: para alunos dos cursos de graduação e pósgraduação. 6 ed. São Paulo: Loyola, 2011. 146p.

RESENDE, J.C.; FREITAS, A.F.; PEREIRA, R.A.N. et al. Determinantes de lucratividade em fazendas leiteiras de Minas Gerais. Arquivo Brasileiro de Medicina Veterinária e Zootecnia, v.68, n.4, p.1053-1061, 2016.

SANT'ANNA, A.C.; GRANCO, G.; BERGTOLD, J. et al. Os desafios da expansão da cana-de-açúcar: como pensam e agem arrendatários e produtores? Radar, v.39, p.39-48, 2015.

SATOLO, L.F.; BACCHI, M.R.P. Dinâmica econômica das flutuações na produção de cana-de-açúcar. Economia Aplicada, v.13, n.3, p.377-397, 2009.

SAUER, S.; PIETRAFESA, J.P. Cana de açúcar, financiamento público e produção de alimentos no cerrado. Campo-Território: revista de geografia agrária, v.7, n.14, p.1-29, 2012.

Recebido para publicação em 28/9/2017 e aprovado em 06/12/2017 